\title{
PENGARUH MODEL PEMBELAJARAN KOOPERATIF TERHADAP HASIL BELAJAR ATLETIK NOMOR TOLAK DITINJAU DARI KEKUATAN OTOT LENGAN
}

\author{
Lisa Marina Lambei ${ }^{1}$, I Nyoman Kanca ${ }^{2}$, Made Agus Wijaya ${ }^{3}$ \\ ${ }^{1}$ Prodi Pendidikan Olahraga Pasca Sarjana, Universitas Pendidikan Ganesha \\ Singaraja, Indonesia \\ ${ }^{2,3}$ Prodi Pendidikan Jasmani, Kesehatan dan Rekreasi, \\ Universitas Pendidikan Ganesha \\ Singaraja, Indonesia \\ e-mail: lisamarina02@gmail.com, kanca.nyoman@undiksha.ac.id, \\ wijaya.madeagus@undiksha.ac.id
}

\begin{abstract}
Abstrak
Penelitian ini bertujuan untuk mengetahui pengaruh model pembelajaran kooperatif TGT dan Jigsaw terhadap hasil belajar tolak peluru gaya O'Brien ditinjau dari kekuatan otot lengan. Penelitian ini menggunakan desain eksperimen dengan treatment by level $2 \times 2$. Populasi penelitian yang digunakan adalah peserta didik kelas XI SMA Negeri 1 Singaraja tahun pelajaran 2019/2020, yang terdiri dari 13 kelas yang berjumlah 465 orang, Sampel penelitan ini diambil dengan cara group random sampling. Teknik analisis data menggunakan anava 2 jalur pada taraf signifikansi 0,05 . Hasil penelitian menunjukkan : (1) hasil belajar tolak peluru gaya O'Brien peserta didik yang mengikuti model pembelajaran kooperatif tipe Jigsaw lebih tinggi daripada peserta didik yang mengikuti model pembelajaran kooperatif TGT, (2) terdapat interaksi antara model pembelajaran dan kekuatan otot lengan terhadap hasil belajar peserta didik (3) model pembelajaran kooperatif Jigsaw memberikan hasil belajar yang lebih baik dibandingkan dengan yang dibelajarkan dengan model pembelajaran kooperatif TGT pada kelompok peserta didik yang memiliki kekuatan otot lengan yang kuat, dan (4) hasil belajar peserta didik yang mengikuti model pembelajaran kooperatif Jigsaw lebih baik dibandingkan yang mengikuti model pembelajaran kooperatif TGT pada kelompok yang memiliki kekuatan otot lengan yang lemah. Kesimpulan dari penelitian ini adalah terdapat perbedaan pengaruh model pembelajaran kooperatif TGT dan Jigsaw terhadap hasil belajar tolak peluru gaya O'Brien ditinjau dari kekuatan otot lengan.
\end{abstract}

Kata kunci: tolak peluru, model kooperatif, jigsaw, TGT, otot lengan

\begin{abstract}
This study aimed at finding out the effect of TGT and Jigsaw type of cooperative learning models on the learning outcome in o'brien's style shot put viewed from arm muscular strength. This study was using an experimental design with treatment by level $2 \times 2$. The population used for this research was students of class XI in the academic year 2019/2020 from SMA Negeri 1 Singaraja, which consisted of 13 classes and having 465 students. The research sample was taken by means of random group. sampling. The data analysis technique was using 2-way ANOVA at a significance level of 0.05 .The results showed: (1) O'Brien-style learning outcomes of students who follow the Jigsaw are higher than students who follow the TGT cooperative learning models, (2) there is an interaction between the learning model and arm muscle strength on the learning outcomes, (3) the learning outcomes of students who follow the Jigsaw are higher than students who follow the TGT cooperative learning models in groups with strong arm muscle strengt, and 4) the learning outcomes of students who follow the Jigsaw are higher than students who follow the TGT cooperative learning models in groups with weak arm muscle. It can be concluded that
\end{abstract}


there are differences in the effect of the TGT and Jigsaw cooperative learning models on the learning outcomes of O'Brien's shot put in terms of arm muscle strength.

Keywords: shot put, cooperative learning, Jigsaw, TGT, arm muscle

\section{PENDAHULUAN}

Pembelajaran Pendidikan Jasmani, Olahraga, dan Kesehatan (PJOK) pada Kurikulum 2013 bertujuan agar peserta didik memiliki kemampuan mengembangkan keterampilan pengelolaan diri dalam upaya pengembangan dan pemeliharaan kebugaran jasmani,serta pola hidup sehat melalui berbagai aktivitas jasmani dan olahraga yang terpilih, meningkatkan pertumbuhan fisik dan pengembangan psikis yang lebih baik, meningkatkan kemampuan dan keterampilan gerak dasar, meletakkan landasan karakter moral yang kuat melalui internalisasi nilai-nilai yang terkandung di dalam PJOK, mengembangkan sikap sportif, jujur, disiplin, bertanggungjawab, kerjasama, percaya diri dan demokratis. Kanca (2010) menyatakan bahwa pembelajaran PJOK dilakukan dengan karakter pembelajaran yang unik (khas) dibandingkan pembelajaran umum lainnya, sehingga menuntut adanya keahlian khusus bagi seseorang yang berprofesi sebagai guru PJOK. Guru memberikan pembelajaran kepada peserta didik agar memahami materi PJOK, salah satu yang ada pada nomor atletik yaitu tolak peluru. Berdasarkan ruang lingkup PJOK atletik terdapat pada permainan dan olahraga. Atletik merupakan gabungan dari beberapa jenis olahraga yang secara garis besar dapat dikelompokkan menjadi jalan, lari, lempar, tolak, dan lompat. Tolak peluru merupakan suatu bentuk gerakan menolak atau mendorong suatu benda yang bundar menyerupai bola (peluru). Peluru umumnya terbuat dari logam dengan berat yang ditentukan. Prosedur gerakan tolak peluru dilakukan dari dorongan bahu dengan satu tangan untuk mencapai jarak yang sejauh-jauhnya. Tolak peluru gaya membelakangi (O’brien) adalah gaya tolak peluru yang dilakukan dengan cara membelakangi arah tolakan.

Berdasarkan hasil pengamatan dan observasi yang dilakukan bersama-sama dengan guru PJOK di SMA Negeri 1 Singaraja materi tolak peluru pada peserta didik kelas XI memperlihatkan hasil sebagai berikut: (1) kurangnya kerjasama antar peserta didik dalam menyelesaikan suatu permasalahan yang terkait dengan materi pembelajaran, (2) dalam penyampaian materi guru masih mendominasi sehingga komunikasi yang terjadi cenderung satu arah, (3) kurangnya variasi dalam proses pembelajaran sehingga peserta didik kurang aktif, (4) model pembelajaran yang diterapkan cenderung konvensional sehingga peserta didik menjadi kurang termotivasi belajar, (5) keterlibatan peserta didik dalam mencari informasi terkait materi belum terlihat, cenderung menunggu informasi yang diberikan oleh guru, dan (6) suasana pembelajaran menjadi kurang kondusif serta cenderung membosankan.

Keberhasilan pembelajaran ditentukan oleh berbagai faktor, salah di antara faktor-faktor tersebut adalah penggunaan model pembelajaran yang mampu meningkatkan partisipasi aktif peserta didik dalam belajar. Berbagai model pembelajaran dikenal di Indonesia, salah satunya adalah model pembelajaran kooperatif. Menurut Trianto, (2007: 42) model pembelajaran kooperatif merupakan sebuah model pembelajaran dalam kelompok yang melibatkan peserta didik bekerja secara berkolaborasi untuk mencapai tujuan bersama. Unsur pertama model pembelajaran kooperatif adalah saling ketergantungan positif. Unsur kedua pembelajaran kooperatif adalah tanggungjawab individual yang membentuk setiap anggota menjadi pribadi yang kuat. Terdapat berbagai model pembelajaran kooperatif yang dapat diterapkan dalam pembelajaranPJOK, seperti Team Games Tournament (TGT), Jigsaw, Student Teams Achievemet Divisions (STAD), Group Investigation (GI), 
Think Pair Share (TPS), dan Numbered Head Together (NHT). Pada penelitian ini peneliti tertarik pada model pembelajaran kooperatif tipe Teams Games Tournament (TGT) dan model pembelajaran kooperatif tipe Jigsaw. Model pembelajaran kooperatif tipe TGT mengandung unsur permainan dan kerjasama kelompok sehingga peserta didik dapat belajar atau memecahkan masalah dengan sungguh-sungguh. Dalam model pembelajaran kooperatif tipe TGT seluruh peserta didik tanpa membeda-bedakan status terlibat aktif dan berperan sebagai tutor sebaya. Berdasarkan hasil penelitian yang dilakukan oleh Santosa (2019), model pembelajaran kooperatif TGT efektif untuk meningkatkan kualitas proses (kemampuan koneksi siswa, keaktifan siswa, motivasi belajar siswa, dan pemahaman siswa) maupun hasil belajar.

Sementara, model pembelajaran kooperatif Jigsaw adalah menitik beratkan kepada kerja kelompok peserta didik dalam bentuk kelompok kecil. Seperti yang diungkapkan Lie (2004: 73) bahwa model pembelajaran kooperatif tipe Jigsaw merupakan model belajar kooperatif dimana peserta didik belajar dalam kelompok kecil yang terdiri atas 4-6 orang secara heterogen dan bekerja sama, saling tergantung secara positif dan bertanggung jawab secara mandiri. Dalam tipe Jigsaw ini peserta didik memiliki banyak kesempatan untuk mengemukakan pendapat, mengolah informasi yang didapat dan dapat meningkatkan keterampilan berkomunikasi. Anggota kelompok bertanggung jawab atas keberhasilan kelompoknya dan ketuntasan bagian materi yang dipelajari, dan dapat menyampaikan materi yang dipelajarinya itu kepada kelompoknya (Rusman, 2008: 203). Ciri-ciri Jigsaw adalah setiap anggota tim terdiri dari 4-6 orang yang disebut kelompok asal. Kelompok asal tersebut dibagi lagi menjadi kelompok ahli. Kelompok ahli dari masing-masing kelompok asal berdiskusi sesuai keahliannya, dan kelompok ahli kembali ke kelompok asal untuk saling bertukar informasi. Terdapat empat langkah dalam merencanakan kegiatan jigsaw, yaitu: menentukan tujuan belajar, menyiapkan panduan belajar, membentuk tim peserta didik, dan mendukung presentasi pakar. Berdasarkan latar belakang tersebut maka dikaji pengaruh model pembelajaran kooperatif (Jigsaw dan TGT) terhadap hasil belajar tolak peluru gaya O'brien ditinjau dari kekuatan otot peserta didik

\section{METODE}

Rancangan penelitian menggunakan desain eksperimen dengan treatment by level $2 \times 2$. Desain faktorial digunakan untuk melakukan eksperimen dengan dua variabel atau lebih. Dalam penelitian ini terdiri dari dua variabel bebas yang dimanipulasi, yaitu faktor model pembelajaran yang terdiri dari model pembelajaran kooperatif tipe TGT dan tipe Jigsaw dan variabel kemampuan gerak khusus yang terbagi atas kekuatan otot lengan yang kuat dan kekuatan otot lengan yang lemah, sebagaimana digambarkan pada tabel 1 berikut. 
Tabel 1. Desain Treatment by Level $2 \times 2$

\begin{tabular}{ccc}
\hline & $\begin{array}{c}\text { Kooperatif tipe TGT } \\
\text { (A1) }\end{array}$ & $\begin{array}{c}\text { Kooperatif tipe } \\
\text { Jigsaw (A2) }\end{array}$ \\
\hline $\begin{array}{c}\text { Kekuatan otot lengan } \\
\text { kuat (B1) }\end{array}$ & A1B1 & A2B1 \\
$\begin{array}{c}\text { Kekuatan otot lengan } \\
\text { lemah (B2) }\end{array}$ & A1B2 & A2B2 \\
\hline
\end{tabular}

Keterangan

A1 : model pembelajaran kooperatif tipe TGT

A2 : model pembelajaran kooperatif tipe jigsaw

B1 : Kekuatan otot lengan kuat

B2 : Kekuatan otot lengan lemah

A1B1: gaya mengajar model pembelajaran kooperatif tipe TGT pada peserta didik yang memiliki kekuatan otot lengan kuat

A1B2: gaya mengajar model pembelajaran kooperatif tipe TGT pada peserta didik yang memiliki kekuatan otot lengan lemah

A2B1: gaya mengajar model pembelajaran kooperatif tipe Jigsaw pada peserta didik yang memiliki kekuatan otot lengan kuat

A2B2: gaya mengajar model pembelajaran kooperatif tipe Jigsaw pada peserta didik yang memiliki kekuatan otot lengan lemah

Populasi penelitian adalah peserta didik kelas XI SMA Negeri 1 Singaraja tahun pelajaran 2019/2020 yang berjumlah 465 orang. Sampel penelitan ini diambil dengan cara group random sampling. Model pembelajaran yang diterapkan menggunakan dua varians, yaitu model pembelajaran kooperatif tipe TGT dan model pembelajaran kooperatif tipe Jigsaw. Faktor pemilahnya adalah variabel moderator kekuatan otot lengan peserta didik. Varians kekuatan otot lengan terdiri atas dua tingkatan yaitu kekuatan otot lengan kuat adalah peserta didik yang termasuk dalam $27 \%$ skor golongan atas (upper group) dan kategori kelompok kekuatan otot lengan lemah adalah peserta didik yang termasuk ke dalam $27 \%$ skor bawah (lower group) setelah data di urutkan dari yang paling besar ke yang paling kecil (Dantes, 2012: 110). Data yang dikumpulkan meliputi data hasil belajar tolak peluru gaya O'Brein dan kekuatan otot lengan peserta didik. Data hasil belajar dikumpulkan dengan menggunakan instrument hasil belajar berupa tes unjuk kerja, sedangkan data kekuatan otot lengan menggunakan tes push up 30 detik. Data dianalisis menggunakan uji ANAVA dua jalur dengan bantuan IBM SPSS Statistics 19

\section{HASIL DAN PEMBAHASAN \\ Hasil}

Data hasil penelitian secara lengkap lengkap mengenai hasil belajar tolak peluru gaya O'Brein peserta didik disajikan pada tabel 2. 
Tabel 2. Rekapitulasi Hasil Perhitungan Skor Hasil Belajar Tolak Peluru Gaya O’Brien

\begin{tabular}{cccccccc}
\hline $\begin{array}{c}\text { Statistik } \\
\text { Kelompok }\end{array}$ & Mean & $\begin{array}{c}\text { Standar } \\
\text { Deviasi }\end{array}$ & Varians & Modus & Median & $\begin{array}{c}\text { Skor } \\
\text { Min }\end{array}$ & $\begin{array}{c}\text { Skor } \\
\text { Max }\end{array}$ \\
\hline $\mathrm{A}_{1}$ & 61,88 & 11,84 & 140,23 & 55 & 57,5 & 45 & 80 \\
$\mathrm{~A}_{2}$ & 74,53 & 9,13 & 83,37 & 70 & 75 & 60 & 90 \\
$\mathrm{~B}_{1}$ & 73,91 & 10,13 & 102,71 & 75 & 75 & 55 & 90 \\
$\mathrm{~B}_{2}$ & 62,50 & 11,66 & 135,94 & 70 & 62,5 & 45 & 85 \\
$\mathrm{~A}_{1} \mathrm{~B}_{1}$ & 70,31 & 8,92 & 79,59 & 80 & 72,5 & 55 & 80 \\
$\mathrm{~A}_{1} \mathrm{~B}_{2}$ & 53,44 & 7,65 & 58,50 & 55 & 55 & 45 & 70 \\
$\mathrm{~A}_{2} \mathrm{~B}_{1}$ & 77,50 & 10,00 & 100,00 & 90 & 75 & 65 & 90 \\
$\mathrm{~A}_{2} \mathrm{~B}_{2}$ & 71,56 & 7,01 & 49,12 & 70 & 70 & 60 & 85 \\
\hline
\end{tabular}

Keterangan :

$A_{1}$ : Model Pembelajaran Kooperatif tipe TGT

$A_{2}$ : Model Pembelajaran Kooperatif tipe Jigsaw

$B_{1}$ : Kekuatan otot lengan kuat

$B_{2}$ : Kekuatan otot lengan lemah

$A_{1} B_{1}$ : Kelompok model pembelajaran Kooperatif tipe TGT pada siswa yang memiliki kekuatan otot lengan kuat

$A_{1} B_{2}$ : Kelompok model pembelajaran Kooperatif tipe TGT pada siswa yang memiliki kekuatan otot lengan lemah

$\mathrm{A}_{2} \mathrm{~B}_{1} \quad$ : Kelompok model pembelajaran Kooperatif tipe Jigsaw pada siswa yang memiliki kekuatan otot lengan kuat

$\mathrm{A}_{2} \mathrm{~B}_{2}$ : Kelompok model pembelajaran Kooperatif tipe Jigsaw pada siswa yang memiliki kekuatan otot lengan lemah

Pengujian hipotesis penelitian yang diajukan dalam penelitian ini dilakukan dengan analisis inferensial dengan program IBM SPSS Statistics 19. Berdasarkan hasil analisis dengan program IBM SPSS Statistics 19, diperoleh taraf signifikansi (Sig.) kolom $=0,000<0,05$ sehingga hal tersebut mengandung makna bahwa terdapat perbedaan hasil belajar Tolak Peluru Gaya O'Brien antara peserta didik yang mengikuti model pembelajaran kooperatif tipe TGT dengan peserta didik yang mengikuti model pembelajaran Jigsaw. Berdasarkan hasil analisis dengan program IBM SPSS Statistics 19, diperoleh taraf signifikansi (Sig.) baris $=0,000<0,05$ sehingga dapat disimpulkan bahwa terdapat perbedaan hasil belajar Tolak Peluru Gaya O'Brien antara peserta didik yang memiliki kekuatan otot lengan kuat dengan yang memiliki kekuatan otot lengan lemah. Berdasarkan hasil analisis dengan program IBM SPSS Statistics 19, diperoleh taraf signifikansi (Sig.) baris $\times$ kolom $=0,015<0,05$ sehingga dapat disimpulkan bahwa terdapat pengaruh interaksi antara model pembelajaran kooperatif dan kekuatan otot lengan terhadap hasil belajar Tolak Peluru Gaya O'Brien.

Karena skor rerata peserta didik yang belajar dengan model pembelajaran kooperatif tipe TGT pada kelompok peserta didik dengan kekuatan otot lengan kuat = 70,313 kurang dari skor rerata peserta didik yang belajar dengan model pembelajaran kooperatif tipe Jigsaw pada kelompok peserta didik dengan kekuatan otot lengan kuat = 77,500 maka dapat disimpulkan bahwa hasil belajar peserta didik yang belajar dengan model pembelajaran kooperatif tipe Jigsaw lebih baik daripada peserta didik yang belajar dengan model pembelajaran kooperatif tipe TGT pada kelompok peserta didik dengan kekuatan otot lengan kuat. Karena skor rerata peserta didik yang belajar dengan model pembelajaran kooperatif tipe TGT pada kelompok peserta didik dengan kekuatan otot 
lengan lemah $=53,438$ kurang dari skor rerata peserta didik yang belajar dengan model pembelajaran kooperatif tipe Jigsaw pada kelompok peserta didik dengan kekuatan otot lengan lemah $=71,563$ maka dapat disimpulkan bahwa hasil belajar peserta didik yang belajar dengan model pembelajaran kooperatif tipe Jigsaw lebih baik daripada peserta didik yang belajar dengan model pembelajaran kooperatif tipe TGT pada kelompok peserta didik dengan kekuatan otot lengan lemah.

\section{Pembahasan}

Berdasarkan hasil penelitian diperoleh hasil bahwa terdapat pengaruh model pembelajaran kooperatif TGT dan Jigsaw terhadap hasil belajar tolak peluru. Baik model pembelajaran TGT dan Jigsaw memberikan pengaruh yang positif terhadap hasil belajar tolak peluru. Melalui model pembelajaran kooperatif, peserta didik diajar untuk bekerja sama dan bertanggung jawab terhadap kelompokknya. Karena dalam pembelajaran kooperatif keberhasilan kelompok tergantung dan dipengaruhi oleh keberhasilan masing-masing individu dalam kelompoknya (Slavin, 2010). Penelitian mengenai efektifitas model pembelajaran kooperatif TGT pernah diteliti oleh Putra (2018) yang menemukan bahwa model pembelajaran TGT memberikan pengaruh yang signifikan terhadap hasil belajar bola voli yaitu passing bawah sebesar $48,12 \%$ dan passing atas sebesar $49,10 \%$. Sedangkan efektifitas model pembelajaran Jigsaw pernah diteliti oleh Spyanawati (2017) yang menemukan bahwa model pembelajaran kooperatif jigsaw berpengaruh terhadap hasil belajar pencak silat terutama pada kelompok mahasiswa dengan motivasi tinggi.

Hasil penelitian menunjukkan ada perbedaan pengaruh antara kopperatif TGT dan Jigsaw, dimana model pembelajaran Jigsaw memberikan pengaruh yang lebih baik dibandingkan dengan model pembelajaran TGT. Karakteristik pembelajaran tolak peluru yang merupakan rangkaian gerakan yang terdiri dari dari 5 tahapan (memegang peluru, meletakkan peluru, gerakan awalan, gerakan menolak peluru dan gerakan akhiran) memungkinkan membagi peserta didik kedalam kelompok kecil untuk mendiskusikan masing-masing tahapan secara maksimal di kelompok ahli kemudian menyampaikan hasilnya kepada kelompok asalnya. Hal ini mampu menambah tanggung jawab peserta didik untuk menguasai bidang keahliannya masing-masing untuk nanti saling berbagi informasi dengan kelompok asalnya. Melalui model pembelajaran jigsaw dapat menumbuhkan kegairahan dan semangat kerja sama, (2) meningkatkan motivasi, (3) saling menghargai, (4) memberikan peluang untuk menyampaikan gagasan secara terbuka, (5) Melatih peserta didik agar mampu berkomunikasi secara efektif (Abdullah, 2016). Penelitian mengenai model pembelajaran Jigsaw dan TGT juga pernah dilakukan oleh Melani Ulfah (2019) yang mengemukakan ada perbedaan pengaruh antara pembelajaran TGT dengan pembelajaran Jigsaw terhadap hasil belajar. Hasil penelitian menunjukkan hasil belajar menggunakan pembelajaran Jigsaw lebih baik dengan nilai rata-rata 82,66 dibandingkan dengan menggunakan pembelajaran TGT dengan nilai rata-rata 78,77. Senada dengan itu Ratnasari (2019) menunjukkan adanya peningkatkan hasil belajar passing bola voli dengan penerapan model pembelajaran kooperatif TGT dan Jigsaw dengan hasil yaitu : (1) nilai keterampilan passing atas meningkat sebesar $35,9 \%$ dan passing bawah sebesar $43,7 \%$ dengan diterapkannya model pembelajaran kooperatif TGT, dan (2) terjadi peningkatan nilai keterampilan passing atas sebesar $46,1 \%$ dan passing bawah sebesar $44,4 \%$ dengan diterapkannya model pembelajaran kooperatif Jigsaw. 


\section{SIMPULAN DAN SARAN \\ Simpulan}

Berdasarkan hasil analisis data dan pembahasan, maka beberapa simpulan dari penelitian ini antara lain sebagai berikut:

1. Terdapat perbedaan hasil belajar tolak peluru gaya O'Brien yang signifikan antara kelompok peserta didik, yang mengikuti model pembelajaran kooperatif tipe Jigsaw lebih baik dari model pembelajaran kooperatif tipeTGT.

2. Terdapat interaksi yang siginifikan antara model pembelajaran dengan kekuatan otot lengan terhadap hasil belajar tolak peluru gaya O'Brien pada peserta didik.

3. Terdapat perbedaan hasil belajar yang signifikan antara peserta didik yang belajar menggunakan model pembelajaran kooperatif TGT dengan peserta didik yang belajar menggunakan model pembelajaran kooperatif Jigsaw. Bahwa model pembelajaran kooperatif jigsaw memberikan hasil yang lebih baik dibandingkan dengan peserta didik yang belajar menggunakan model pembelajaran kooperatif TGT pada kelompok peserta didik yang memiliki kekuatan otot lengan kuat.

4. Terdapat perbedaan hasil belajar antara peserta didik yang belajar menggunakan model pembelajaran kooperatif TGT dengan peserta didik yang belajar tolak peluru gaya O'Brien pada peserta didik yang menggunakan model pembelajaran kooperatif TGT. Bahwa model pembelajaran kooperatif Jigsaw memberikan hasil yang lebih baik dibandingkan dengan peserta didik yang belajar menggunakan model pembelajaran kooperatif TGT pada kelompok peserta didik yang memiliki kekuatan otot lengan lemah.

\section{Saran}

Beberapa saran yang dikemukakan sehubungan dengan hasil yang diperoleh dalam penelitian ini sebagai berikut,

1. Model pembelajaran kooperatif tipe TGT dan Jigsaw di tinjau dari kekuatan otot lengan hendaknya terus diperkenalkan dan dikembangkan oleh guru melalui berbagai wadah organisasi keguruan sebagai salah satu model pembelajaran yang mampu memberikan nuansa baru dalam proses pembelajaran untuk menggali dan mengembangkan potensi yang dimiliki oleh peserta didik secara optimal.

2. Kepada guru PJOK, diharapkan mencoba menerapkan model pembelajaran kooperatif tipe TGT dan Jigsaw karena secara empirik model ini telah terbukti mampu meningkatkan kreativitas siswa untuk engeksplorasi dan megelaborasi materi pembelajaran sehingga mampu meningkatkan hasil belajar peserta didik

\section{DAFTAR PUSTAKA}

Abdullah, R. (2016). Pengaruh Penerapan Model Pembelajaran Kooperatif Tipe Jigsaw pada Mata Pelajaran Kimia di Madrasah Aliyah. Lantanida, 4(1).

Dantes, N. (2012). Metode Penelitian. Andi.

Kanca, I. N. (2010). Metode Penelitian Pengajaran Pendidikan Jasmani dan Olahraga. Universitas Pendidikan Ganesha.

Lie, A. (2004). Mempraktekan Cooperative Learning. PT. Gransindo.

Melani Ulfah, S. (2019). Komparasi Hasil Belajar Teams Games Tournaments (TGT) dan Jigsaw pada Siswa Kelas IV SD Muhammadiyah Bekonang Tahun Pelajaran 2018/2019. Universitas Muhammadiyah Surakarta.

Putra, B. U. (2018). Pengaruh Model Pembelajaran Kooperatif Tipe Teams Games Jurnal Penjakora | 32 
Tournament (TGT) Terhadap Hasil Belajar Passing Bawah dan Passing Atas Bola Voli pada Kelas VII di SMP Muhammadiyah 8 Tanggulangin. Jurnal Pendidikan Olahraga Dan Kesehatan, 7(1).

Ratnasari, B. Y. (2019). Perbandingan Evektivitas Model Pembelajaran Kooperatif Tipe STAD TGT dan Jigsaw terhadap Hasil Belajar Passing Atas dan Bawah Bolavoli pada Siswa Kelas XI Sman I Pujut Lombok Tengah. Satria, 2(1), 10-14.

Rusman. (2008). Pembelajaran Kooperatif Tipe Jigsaw. Depdiknas.

Santosa, D. S. S. (President U. (2019). Manfaat Pembelajaran Kooperatif Team games Tournament (TGT) Dalam Pembelajaran. Statistical Field Theor, 53(9), 1689-1699.

Slavin, R. L. (2010). Cooperative Learning Teori, Riset dan Praktik. Nusa Media.

Spyanawati, N. L. P. (2017). Pengaruh Model Pembelajaran Dan Motivasi Terhadap Hasil Belajar Teknik Dasar Tendangan Pencak Silat Pada Mahasiswa Jurusan Penjaskesrek Fok Undiksha. JURNAL PENJAKORA, 2(1), 61-72.

Trianto. (2007). Model-model pembelajaran inovatif berorientasi Konstruktivistik. Prestasi Pustaka. 